\title{
Persistent Hemiballismus with Lesions Outside the Subthalamic Nucleus
}

\author{
Anthony E. Lang
}

\begin{abstract}
Two patients are reported with hemiballismus due to lesions in the striatum as documented on CT scan. The involuntary movements persisted for one and five years respectively. A third patient with more typical self-limited hemiballismus had no evidence of a causative lesion on CT scan. It is proposed that lesions outside the subthalamic nucleus of Luys may interfere with the compensatory mechanisms which can result in the spontaneous resolution of hemiballistic movements. None of the patients benefited from the use of sodium valproate therapy, however, pimozide reduced the severity of the dyskinesia in the two with longstanding hemiballismus.
\end{abstract}

RÉSUMÉ: Hémiballisme persistant avec lesion située hors du noyau sous-thalamique Nous rapportons deux cas d'hémiballisme dont les lésions identifiées à la tomodensitométrie cérébrale sont situées au niveau du striatum. Les mouvements involontaires furent observés pendant des périodes de une et cinq années, respectivement. Un troisième patient présentant un hémiballisme plus typique et de durée limitée ne montrait aucune lésion causale à la tomodensitométrie. Nous proposons l'hypothèse que des lésions situées hors le noyau sousthalamique de Luys peuvent interférer avec des mécanismes compensatoires, résultant en une cessation spontanée des mouvements hémiballiques. L'emploi du valproate de sodium chez les trois patients s'avéra inefficace. Cependant le pimozide diminua la sévérité des mouvements chez les deux patients à longue évolution.

Can. J. Neurol. Sci. 1985; 12:125-128

Hemiballismus is probably the most uncommon type of dyskinesia (Koller et al., 1979). The violent flinging nature of the involuntary movements is often extremely disabling. However, patients improve with dopamine antagonistic therapy (Koller et al., 1979) and most cases resolve spontaneously over a period of one week to six months (Hyland and Forman, 1957; Muenter, 1984). Two patients with longstanding hemiballismus ( 1 and 5 years) were found to have CT scan lesions in the contralateral striatum. Similar cases of prolonged hemiballismus are uncommon but well recognized. Review of the literature reveals that most of these also have had lesions outside the region of the subthalamic nucleus. It is proposed that the location of the lesion may be of some importance to the course of hemiballismus. In addition, both of these patients, as well as one case with more typical, self-limited hemiballismus, failed to respond to sodium valproate. Previous reported "responses" could have been due to spontaneous improvement, as exemplified by our third case, since they occurred in patients with a short history of the dyskinesia (Lenton et al., 1981 ; Chandra et al., 1982).

\section{Case Reports}

\section{Patient 1}

A seventy-two year old hypertensive, insulin-dependent diabetic female suddenly developed clumsiness of her left arm and leg. This was followed over the next two days by involuntary flinging movements of these limbs which resulted in frequent bruising. She was treated with small doses of chlorpromazine and diazepam with only a slight reduction in the severity of the movements. She was seen at the Toronto Western Hospital five months after the onset of her symptoms at which time she demonstrated typical hemiballistic movements involving the proximal and distal left arm and leg. In addition, there were smaller amplitude choreiform movements and occasional more prolonged dystonic postures. There was a mild upper motor neurone left facial weakness and a reduction of all sensory modalities in a stocking distribution bilaterally.

A CT scan showed multiple, small poorly-defined areas of decreased density in the region of the basal ganglia on the right side (Figure 1). In addition there were faint minute calcifications within the basal ganglia bilaterally.

The patient was treated with gradually increasing doses of sodium valporate reaching 1.5 grams per day for a total of seventeen days. Despite a maximum plasma level of $121 \mathrm{mg} / \mathrm{L}$ (therapeutic range $40-100$ $\mathrm{mg} / \mathrm{L}$ ) there was no change in the nature or severity of her abnormal movements. Pimozide $2 \mathrm{mg}$ t.i.d. caused a marked improvement in the involuntary movements allowing her to begin using the left arm actively and to walk much more steadily. Reduction in the dosage of pimozide seven months later (one year after the onset of involuntary movements) resulted in an increase in the severity of the dyskinesia.

\section{Patient 2}

This seventy-nine year old Portuguese male gave a poorly-defined history of intermittent black-out spells five years before the onset of his dyskinesia. Shortly after a motor vehicle accident in which he did not suffer head trauma, he had the onset of involuntary movements of the right arm. The severity of the abnormal movements gradually increased 


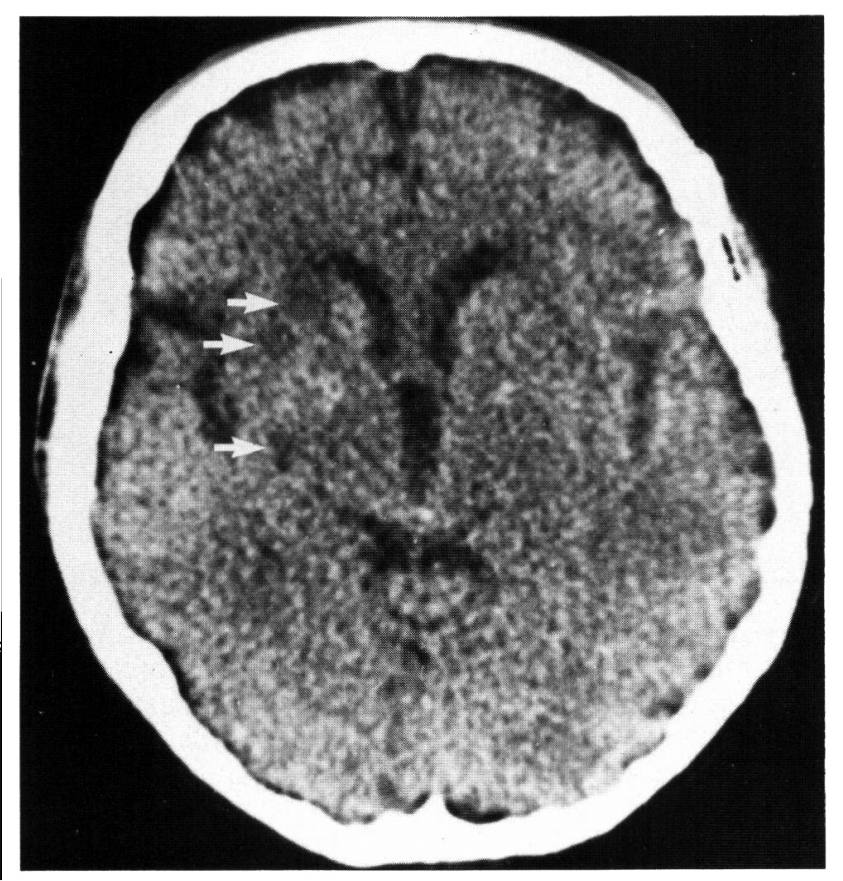

Figure I - Unenhanced CT scan in Patient l showing several areas of reduced density in the region of the right caudate and putamen (arrows). Faint calcification is also present in the basal ganglia on both sides.

and two to three years after they began, his right leg became involved. His family had noticed an impairment in memory and periods of confusion over the year prior to his hospital admission. He had been a heavy drinker and smoker in the past. He was first seen at the Toronto Western Hospital five years after the onset of his movements.

On examination he was cyanotic and short of breath. There were occasional involuntary movements of the tongue and the right side of the face. At rest there were irregular choreiform jerks of the right arm and leg. He developed violent ballistic flinging movements of the proximal arm and leg with any activity, either mental or physical. He had large areas of bruising over the right leg due to repeated trauma from his involuntary movements. He was disorientated to place and demonstrated disturbances of short-term memory. There was a mild subjective reduction in pin-prick and temperature sensation on the right side of the body. Blood pressure was $140 / 70$.

Hematology and biochemistry were unremarkable except for a fasting blood sugar of $175 \mathrm{mg} / \mathrm{dl}$. CSF was normal. A carotid doppler study showed a $35 \%$ stenosis of the right carotid bifurcation. A CT scan demonstrated small well-defined areas of decreased density adjacent to the lateral aspect of the left lateral ventricle in the region of the head of the caudate nucleus (Figure 2). There was no abnormal enhancement or mass effect. In addition there was bilateral dilatation of the lateral ventricles and cortical sulcal enlargement.

Sodium valproate in gradually increasing doses over fourteen days to a maximum of $2.5 \mathrm{~g}$ per day with a resultant blood level of $770 \mathrm{umol} / \mathrm{L}$ (therapeutic range $350-700$ ) did not alter the involuntary movements whatsoever. Pimozide $4 \mathrm{mg}$ b.i.d. resulted in a marked functional improvement with faster, more steady walking and improved dexterity of the hand although clinically there was only a mild to moderate reduction in the severity of involuntary movements.

\section{Patient 3}

This sixty-two year old male had the sudden onset of severe flailing involuntary movements and poorly described pain in the right arm and leg. Past history included heavy smoking, hypertension, gouty nephropathy and a recovered left lateral medullary infarct fourteen years earlier. Initially the severity of the involuntary movements caused several minor injuries to the affected limbs. When examined two weeks later he had persistent choreiform movements of the right arm and leg which frequently became hemiballistic, particularly when he was

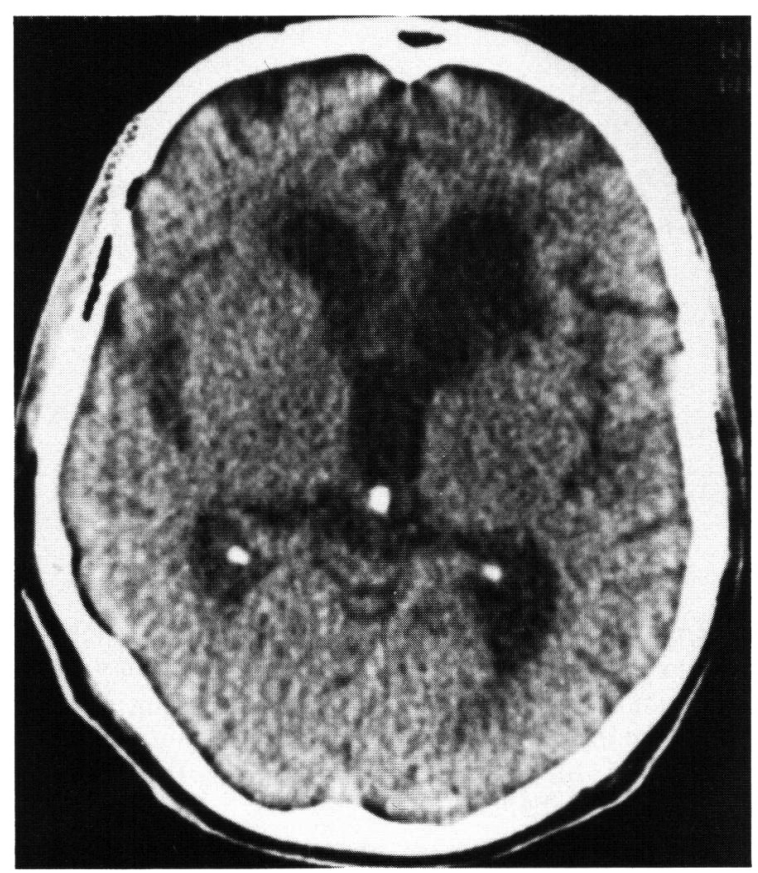

Figure 2 - Unenhanced CT scan in Patient 2 showing focal areas of lucency in the region of the head of the caudate nucleus on the left. Ventricular and cortical sulcal enlargement is also evident.

emotionally upset. There was additional mild pyramidal weakness in these limbs. Pain and temperature sensations were reduced over the right face and body and gag and palatal movement were reduced on the left, probably due to the previous medullary infarct. Blood pressure was $180 / 105$.

CT scan was unremarkable other than an area of possible focal atrophy in the right frontal area. He was treated with sodium valproate up to $1,500 \mathrm{mg}$ per day for a two week period (blood level $320 \mathrm{umol} / \mathrm{L}$ ). During this time there was a gradual resolution of the more severe hemiballistic movements and a reduction in the milder choreiform movements of the right limb. Sodium valproate was discontinued with no change in his clinical status. Indeed the involuntary movements continued to improve so that three weeks later he had only rare choreiform jerks in the right hand and mild repetitive tapping movements of the right foot.

\section{Discussion}

Hemiballistic movements are most commonly caused by a lesion in the contralateral subthalamic nucleus (Whittier, 1947). Melamed and his colleagues (1978) reported such a case with CT scan evidence for focal hemorrhage in the region of the subthalamic nucleus. However, many cases have been documented patholigically with lesions in structures outside the subthalamus and its connections (Whittier, 1947; Schwartz and Burrows, 1960). The most common of these sites is the corpus striatum (caudate and/or putamen). Kase et al. (1981) recently reported a patient with $\mathrm{CT}$ evidence of lacunar infarction in the striatum and Lodder and Baard (1981) reported a patient with paraballism or bilateral ballism after head trauma with hemorrhagic infarction in both corpora striata. The present patients 1 and 2 are further examples of hemiballismus with CT scan evidence of basal ganglia lesions outside the subthalamic region. However, it is impossible to exclude the possibility that the subthalamic nucleus was involved in addition to those areas where abnormalities were clearly demonstrated. 
The relationship between outcome of hemiballismus and the location of the causative lesion(s) has received little attention to date. The prognosis of untreated hemibalismus is variable. Myers (1968) in his review article commented that "favourable outcomes appear to be the exception rather than the rule". However, Hyland and Forman (1957) documented recovery in twelve of fourteen patients within one to twelve weeks of the onset of the movement disorder. In a recent review of the Mayo Clinic experience between 1935 and 1975 Muenter (1984) concluded that "hemiballismus is a benign condition with spontaneous recovery in most cases". Twenty-two of his twentynine patients recovered completely within six months. Our patient 3 is a typical example of this self-limited history.

On the other hand, cases of persistent movements lasting many months to years are also well recognized (Whittier, 1947; Myers, 1968). Six of Muenter's (1984) twenty-nine patients did not recover although two of these cases had some spontaneous improvement. It was not possible to determine how these persistent cases differed from the larger number whose involuntary movements resolved. Hyland and Forman (1957) postulated that lesions sparing the subthalamic nucleus but possibly involving its afferent connections might be associated with a greater chance of spontaneous recovery. However, our patients 1 and 2 with prolonged hemiballismus had prominent striatal lesions. Furthermore, in Schwartz and Burrows' review (1960) a spontaneous recovery occurred in only two of twelve patients suffering from ischemic lesions outside the subthalamic nucleus who survived the acute period. In Whittier's earlier review (1947) of the literature, most patients died in the early stages due to the complications of their movement disorder. Interestingly, of the cases with a prolonged history ( 12 months to 50 years) which are specifically mentioned, none had lesions restricted solely to the subthalamic nucleus. Either the subthalamic nucleus was damaged in addition to contiguous and distant structures (Touche, 1901; Souques \& Bertrand, 1926; von Sántha, 1928; Kulenkampff, 1938; Marcus \& Sjögren, 1938) or this nucleus and its immediate connections were completely spared (Fragnito \& Scarpini, 1926; Wilson, 1929). This experience suggests that lesions outside the subthalamic nucleus, most notably those involving the striatum as in the present two cases, could interfere with the adaptation mechanisms which account for the spontaneous resolution of hemiballistic movements.

Finally, mention should be made about the failure of sodium valproate therapy in these patients. Most investigators view ballism and chorea on a continuim rather than as truly distinct entities (Koller et al., 1979). Antidopaminergic drugs such as the neuroleptics and dopamine depleting agents (e.g., reserpine, tetrabenazine) remain the most effective drug therapy for these movement disorders. In patients severely disabled by lifethreatening ballistic movements, the use of antidopaminergic agents may assist in making survival and a good prognosis the rule (Klawans et al., 1976). However, the usefulness of sodium valproate in choreiform movement disorders is controversial. It has been reported effective in ballism (Lenton et al., 1981; Chandra et al., 1981) as well as Syndenham's chorea (MacLachlan, 1981) and post-traumatic choreoathetosis (Chandra et al., 1983). Variable results are reported in tardive dyskinesia (Linnoila et al., 1976; Chen, 1980). Levodopa-induced dyskinesias have either not improved (Price et al., 1978) or worsened (Nutt et al., 1979) and Huntington's chorea has not responded (Shoulson et al., 1976; Pearce et al., 1977). Unlike the two previous reported cases (Lenton et al., 1981; Chandra et al., 1982) neither of our first two patients with longstanding dyskinesia had a reduction in the severity of their hemiballismus with sodium valproate. One might question whether the long duration of involuntary movements indicates an atypical pharmacological mechanism accounting for hemiballismus in these cases. However, the response of both patients to pimozide, a highly selective postsynaptic dopamine receptor antagonist, favours a pathopharmacology similar to the more usual short-lived cases of ballism (Klawans et al., 1976). Had these patients benefited from sodium valproate the long duration of abnormal movements would have argued against the possibility of a coincidental spontaneous recovery. The involuntary movements in patient 3 gradually lessened during valproate therapy, however the dyskinesia continued to improve at the same rate after the drug was withdrawn. The short history of involuntary movements in the earlier reports (Lenton et al., 1981; Chandra et al., 1982) and the failure of the dyskinesia to return on discontinuing valproate three days later in one case (Chandra et al., 1982), suggests that these reported cases could represent examples of similar spontaneous improvement coincident with drug treatment.

\section{ACKNOWLEDGEMENTS}

Special thanks to Dr. R.D.G. Blair for referring Patient 3 and for helpful advice in the preparation of the manuscript.

\section{REFERENCES}

Chandra V, Spunt AL, Rusinowitz MS (1983) Treatment of posttraumatic choreoathetosis with sodium valproate. J Neurol Neurosurg Psychiat 46: 963.

Chandra V, Wharton S, Spunt AL (1982) Amelioration of hemiballismus with sodium valproate. Ann Neurol 12: 407

Chen CP (1980) Tardive Dyskinesia: Controlled studies of several therapeutic agents. In: Tardive Dyskinesia Research and Treatment. Edited by WE Fann, RC Smith, JM Davis and EF Domino. SP Medical and Scientific Books, New York, pp 429-469.

Fragnito O, Scarpini V (1926) Reperto anatomopathologico in un caso di emicorea sintomatica. Riv di patol nervment 31: 524-531.

Hyland HH, Forman DM (1957) Prognosis in Hemiballism. Neurology 7: $381-391$

Kase CS, Maulsby GO, de Juan E, Mohr JP (1981) Hemichoreahemiballism and lacunar infarction in the basal ganglia. Neurology 31: $452-455$.

Klawans HL, Moses H, Nausieda PA, Bergen D, Weiner WJ (1976) Treatment and prognosis of hemiballismus. New Eng J Med 295: 1348-1350.

Koller WC, Weiner WJ, Nausieda PA, Klawans HL (1979) Pharmacology of Ballismus. Clin Neuropharmacol 4: 157-174.

Kulenkampff D (1938) Ueber die sogenannte Hemichorea posthemiplegica (Hemiballismus) und die Bedeutung der Pyramidenbahnen. Zentralblf Chir 65: 2466-2470.

Lenton RJ, Copti M, Smith RG (1981) Hemiballismus treated with sodium valproate. $\mathrm{Br}$ Med J 283: 17-18.

Linnoila M, Viukari M, Hietala O (1976) Effect of sodium valproate on Tardive Dyskinesia. Brit J Psychiatr 129: 114-119.

Lodder J, Baard WC (1981) Paraballism caused by bilateral hemorrhagic infarction in basal ganglia. Neurology 31: 484-486.

Marcus H, Sjögren H (1938) L'hémiballisme et le corps de Luys. Rev Neurol 70: 1-28.

McLachlan RS (1981) Valproic acid in Sydenham's chorea. Br Med J 283: 274-275.

Melamed E, Horn-Lubetzki I, Reches A, Siew F (1978) Hemiballismus: Detection of focal hemorrhage in subthalamic nucleus by CT scan. Ann Neurol 4: 582.

Muenter MD (1984) Hemiballismus. Neurology 34 (suppl I): 129. 
Myers R (1968) Ballismus I $n$ : Handbook of Clinical Neurology, Volume 6. Edited by PJ Vinken, GW Bruyn. North Holland, Amsterdam, pp 476-490.

Nutt J, William A, Plotkin C, Eng N, Zeigler M, Calne DB (1979) Treatment of Parkinson's disease with sodium valproate: Clinical pharmacological and biochemical observations. Can J Neurol Sci 6: 337-343.

Price PA, Parkes JD, Marsden CD (1978) Sodium valproate in the treatment of levodopa-induced dyskinesia. J Neurol Neurosurg Psychiatry 41: 702-706.

Pearce 1, Heathfield KWG, Pearce JMS (1977) Valproate sodium in Huntington's chorea. Arch Neurol 34: 308-309.

Schwartz GA, Burrows LJ (1960) Hemiballism without involvement of Luy's Body. Arch Neurol 2: 420-434.

Shoulson I, Kartzinel R, Chase TN (1976) Huntington's disease: Treatment with dipropylacetic acid and gamma aminobutyric acid. Neurology 26: 61-63.
Souques A, Bertrand I (1926) Sur la fonction notrice du corps strié, à propos d'un cas d'hémichorée suivi d'autopsie. Rev Neurol 33: 988-1002.

Touche M (1901) Deux cas d'hémichorée organique avec autopsie. Rev Neurol 9: 1080-1081.

von Sántha K (1928) Zur Klinik und Anatomie des Hemiballismus. Arch f Psychiat 84: 664-678.

Whittier JR (1947) Ballism and the subthalamic nucleus (nucleus hypothalamicus; corpus Luysi). Review of the literature and study of thirty cases. Arch Neurol and Psychiatry 58: 672-692.

Wilson SAK (1929) Die Pathogenese der unwillkürlichen Bewegungen mit besonderer Berücksichtingung der Pathologie und Pathogenese der Chorea. Deutsche Ztschr f Nervenh 108: 4-38. 